\title{
Bone marrow in nine cases of clinical glandular fever and a review of the literature
}

\author{
J. F. BOYD AND D. REID \\ From the Brownlee Laboratory, University Department of Infectious Diseases, Ruchill Hospital, Glasgow, \\ and University Department of Pathology, Western Infirmary, Glasgow
}

SYNOPSIS A review of the literature and the findings of a bone marrow examination in nine patients with glandular fever are reported. All marrows showed marked generalized hyperplasia of erythroid, myeloid, megakaryocytic, and reticulum cell elements with a greater or less 'shift to the left' in the first three cell groups. The hyperplasia was maximal in two cases. Another case (the index case which was responsible for initiating this study) showed extremely bizarre cytological features of all four elements, and from many fields in the marrow smears it would have been possible to make a diagnosis of malignant transformation of any of the four marrow components. All these changes had returned to near normality on repeat marrow examination 15 months later.

\section{DIAGNOSIS OF GLANDULAR FEVER}

The syndrome of glandular fever can usually be diagnosed on the basis of history, clinical examination, simple haematology, and the Paul-Bunnell reaction with differential absorption tests when indicated (Davidsohn and Lee, 1964). Bone marrow examination is seldom necessary, although some authors have recommended strongly that this procedure should be routine in order to exclude the possibility of leukaemia, especially when the haemoglobin level or platelet count is below normal and the Paul-Bunnell test is negative (Morrison and Samwick, 1939; Vogel and Bassen, 1939; Mendell, Meranze, and Meranze, 1942; Limarzi, Paul, and Poncher, 1946). The bone marrow findings have been recorded previously by several authors, and the results can be grouped roughly in seven categories.

1 LYMPHOCYTIC AND/OR MONOCYTIC INFILTRATION This has been reported by Du Bois (1930), Freeman (1936), Morrison and Samwick (1939), Israëls (1941), Halcrow, Owen, and Rodger (1943), and Campbell (1948). The first two authors stated that the findings were indistinguishable from leukaemic infiltration. Morrison and Samwick (1939) reported that this infiltration was only found occasionally,

'Present address: Epidemiological Research Laboratory, Public Health Laboratory Service, Colindale Avenue, London, NW9.

Received for publication 12 March 1968. accompanied sometimes by increased erythroid activity in spite of the absence of anaemia, and that the myeloid series showed a mild shift to the left, not as marked as is encountered in agranulocytosis. Israëls noted also mild leucopoietic hyperplasia. Campbell, on the other hand, emphasized the necessity for preparing marrow sections as well as for studying smears. This procedure was by no means routine at the time of his report in which he also noted generalized myeloid hyperplasia in eight of 15 cases studied. Sarcoid-like foci of either reticulum cells, of mononuclear cells, or of glandular fever cells were found in 12 cases.

2 LEUCOPOIETIC HYPERPLASIA This feature has been reported by Vogel and Bassen (1939), Mendell et al (1942), Limarzi et al (1946), and Custer and Smith (1948), as well as by authors in the first group. Vogel and Bassen (1939) and Mendell et al (1942) considered this to be a very useful finding, especially if the patients were children and if leukaemia were suspected. Limarzi et al (1946) found myeloid hyperplasia in 20 of 25 cases examined, megakaryocytic hyperplasia in 15 cases, occasionally reticulum cell or erythroid hyperplasia, and that glandular fever cells were prominent by their absence. Custer and Smith (1948) confirmed this last finding, and also supported the occasional presence of megakaryocytic hyperplasia.

3 SARCOID-LIKE GRANUlOMATA Schleicher (1949), Hovde and Sundberg (1950), and Pease (1956) 
drew attention to this feature of the marrow, although it is clear that Campbell (1948) was the first to report it. Schleicher (1949) reported 'reticuloepithelioid granulomata' without giant cells or necrosis in two cases. One was examined again 12 months later and no abnormality was noted. He concluded that these changes, which he believed were part of a more widespread marrow reticulum cell hyperplasia, were reversible. Hovde and Sundberg (1950) noted in addition hyperplasia in all 23 cases, which was partly erythroid, partly myeloid, and partly megakaryocytic. Granulomata were present in almost half of the series. They also considered lymphocytic infiltration to be an important part of the process. Pease (1956) studied the causes of granulomatous foci in bone marrow. She included infectious mononucleosis in her list, having noted numerous foci in five cases and scanty foci in nine examples of this condition.

4 ERYTHROID AND MEGAKARYOCYTIC HYPERPLASIA These features were recorded by Volpe, Sparks, and Mautner (1953) in one patient who had thrombocytopenic purpura.

5 NO ABNORMALITY DETECTED Scott (1939) reported no abnormality in one case studied and recalled that such a finding does not necessarily exclude the diagnosis of lymphatic leukaemia. Allen and Kellner (1947) failed to note any abnormality in necropsy examination but the marrow was autolytic.

6 REDUCTION OF MEGAKARYOCYTES This was noted by Ogilvie and Parry (1952) in their patient who also suffered from thrombocytopenic purpura. However, they noted also that the $M / E$ ratio was $1.5 / 1.0$ which could indicate at least marked erythroid hyperplasia, and would not exclude simultaneous myeloid hyperplasia.

7 MEgaloblastic MARROW ARREST This was recently reported by Mengel, Wallace, and McDaniel (1964) who considered this finding to be due to temporary 'relative' folate deficiency.

It appears, therefore, that reports of marrow infiltration by lymphocytes and by glandular fever cells occurred most frequently at the period when marrow smears alone were studied. The more recent reports of this finding may be explained by the occurrence of mild to marked hyperplasia of foci of lymphocytes which are occasionally present in normal marrow, while the most consistent findings from the later reports is the presence of generalized marrow hyperplasia with or without sarcoid-like granulomata.

The present investigation developed from ex- perience gained with case 1 . Although earlie $\vec{F}$ writers were at pains to try to differentiate between glandular fever and early acute leukaemia, we wis to draw attention to the possibility of confusing the marrow findings in glandular fever with the myeloc proliferative disorders, including within this group of conditions, Di Guiglielmo's disease, polys cythaemia vera, myeloid leukaemia, megakaryocyti $\overrightarrow{0}$ myelosis, and the malignant reticuloses.

\section{MATERIALS AND METHODS}

The report is based on the study of nine patients witis glandular fever, two of whom, including our index casei had negative Paul-Bunnell tests. These nine patiento were more or less consecutive admissions to hospita\& during 1964 and were selected because they were irg their late teens or older. It was explained to the last eight patients that the marrow examination which we wished to perform was not essential for the diagnosis of their illness but by studying their marrow a guide to the prognosis for case 1 might be obtained. For this reason? children were excluded. The haematological methods are the standard ones used throughout Great Britain (eg Britton, 1963), and the marrow particles were pro. cessed by the method of Hutchison (1953).

\section{CASE REPORTS}

All patients (eight males and one female) were admitted following a history of headache, malaise, night sweats $\bar{D}$ anorexia, sore throat, and fever of six to 14 days duration. Examination showed features varying fromo injection of the throat to classical membrane formation $\mathrm{P}$ over one or both tonsils, fauces and pharynx, accompanied by enlargement of the cervical lymph nodes. Six also had enlargement of the axillary lymph nodes and two has. enlargement of the groin nodes. The liver was tender in two cases, and was mildly enlarged in another two cases. The spleen was palpably enlarged in three cases and was tender in one of these. The peripheral blood findings ando other investigations are recorded in the Table, the atypica $\bar{\beta}$ lymphocytes and monocytes being included with theo normal lymphocytes and monocytes in this instance? (Carter, 1966). Convalescence pursued a normal course and all patients went home within two to three weeks. after admission. Follow-up at one and three months as required showed all patients to be well, although in two instances the liver function tests remained abnormal. These reverted to normal within six months. In anothere two instances the Paul-Bunnell test remained at patho-O logical levels at one month and at eight months re spectively after discharge from hospital. In neither patient whose Paul-Bunnell test was negative on admissionos did the test become positive later, either in hospital or during convalescence.

\section{STERNAL BONE MARROW FINDINGS}

With the aim of confirming the diagnosis in case 1, the first patient to be studied in this series, a marrowo 
TABLE

PERIPHERAL BLOOD FINDINGS IN NINE CASES OF GLANDULAR FEVER ON ADMISSION

$\begin{array}{lllllll}\begin{array}{l}\text { Case } \\ \text { No. }\end{array} & \text { Sex } & \text { Age } & \begin{array}{l}\mathrm{Hb} \\ (\%)\end{array} & \begin{array}{l}\text { WBC } \\ (\text { per } \mathrm{cmm})\end{array} & \frac{\text { Differential WBC }(\%)}{\text { Polymorphs }} & \begin{array}{l}\text { Lymphocytes/Mono- } \\ \text { cytes }\end{array}\end{array}$

Paul-Bunnell Negative

$1 \quad M \quad 33$

$2 \quad M \quad 38$

Paul-Bunnell Positive

$\begin{array}{lll}3 & M & 22 \\ 4 & M & 28 \\ 5 & \text { F } & 17 \\ 6 & M & 24 \\ 7 & M & 22 \\ 8 & M & 22 \\ 9 & M & 27\end{array}$

97
84

104
95
81
91
97
93
96

8,200

22

22

7,500

7,600

11,600

6,400

10,500

9,400

5,400

cytes

examination was carried out. It was hoped that the presence of sarcoid-like follicles similar to the one illustrated in Fig. 1 would be revealed. None was found. Instead, there was marked diffuse hyperplasia affecting erythroid and myeloid elements, and also affecting the megakaryocytes and reticulum cells in a diffuse fashion (Fig. 2). The M/E (myeloid/erythroid) ratio was almost $1 \cdot 0 / 2 \cdot 0$. Erythropoiesis showed marked transitional megaloblastic features, and Howell-Jolly bodies and polyploidy were not infrequent (Fig. 3). Mitosis and binucleate forms occurred not uncommonly, in the absence of haemolytic anaemia (serum bilirubin $0.6 \mathrm{mg}$ per $100 \mathrm{ml}$, reticulocytes $2 \%$ ). The possibility of erythraemia was considered, especially since there was a distinct shift to the left, but these erythroid precursors showed a PASnegative cytoplasm. The myeloid series also showed a shift to the left but there was no arrest of maturation at any particular stage and the features could be explained on the basis of pronounced hyperplasia of the early myeloid elements. Megakaryocytic hyperplasia was very marked and also showed a marked shift to the left. Indeed the appearances were reminiscent of polycythaemia vera, but collections of megakaryoblasts showed 'back-to-back' features in many areas and simulated the Sternberg-Reed giant cells of Hodgkin's disease. The marrow was minimally infiltrated by lymphocytes and it was difficult to find glandular fever cells in the smears, except in those areas where there was some contaminating blood. Although the patient's clinical progress and haematological findings pursued a normal course for glandular fever, it was considered highly desirable, in view of these very florid marrow findings, to repeat this examination when, 15 months later, the peripheral blood was normal in every respect, and only very mild generalized hyperplasia remained (Fig. 4). None of the earlier highly bizarre features of the erythroid series was present. Maturation of both myeloid and erythroid series was normal, and the normal predominance of 'late forms' was present. In spite of these normal features, a smear, stained by the PAS method, was studied once more, and there was no suspicion of erythraemia. No specific treatment had been given meanwhile.

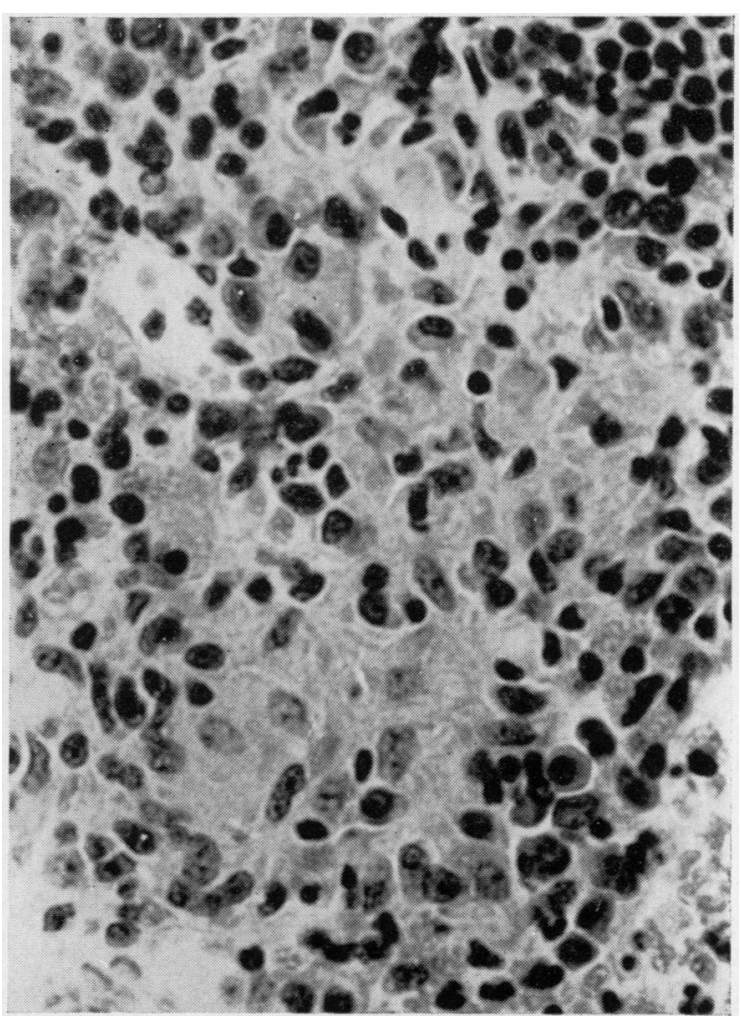

FIG. 1. Sarcoid-like follicle due to reticulum cell hyperplasia in the marrow of a patient with Paul-Bunnell positive glandular fever. $H$, and $E . \times 670$. 


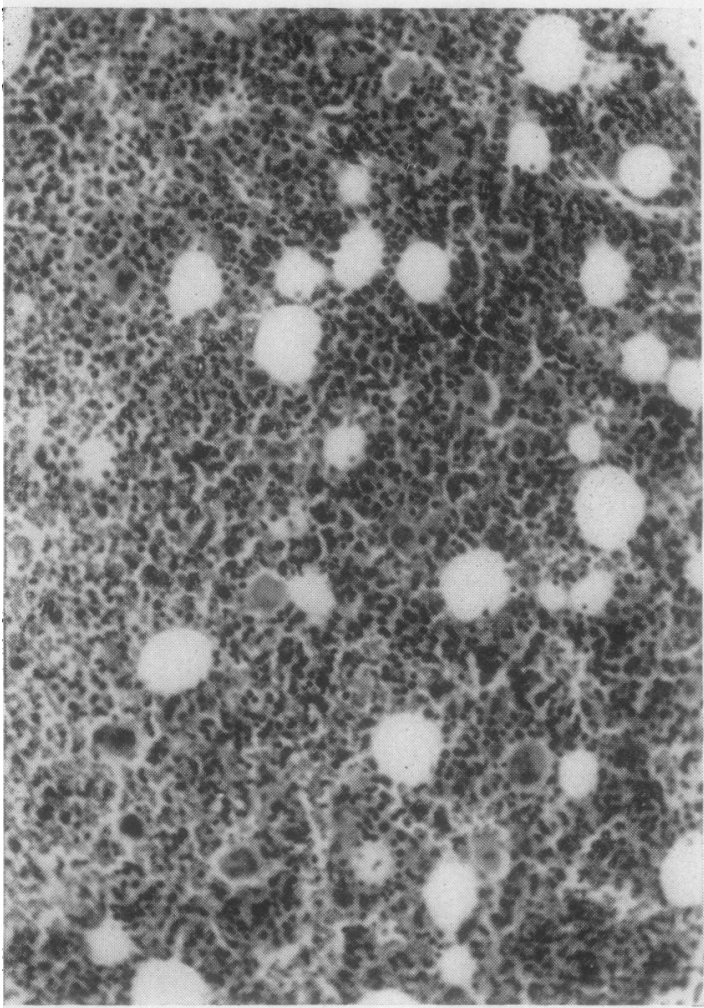

FIG. 2

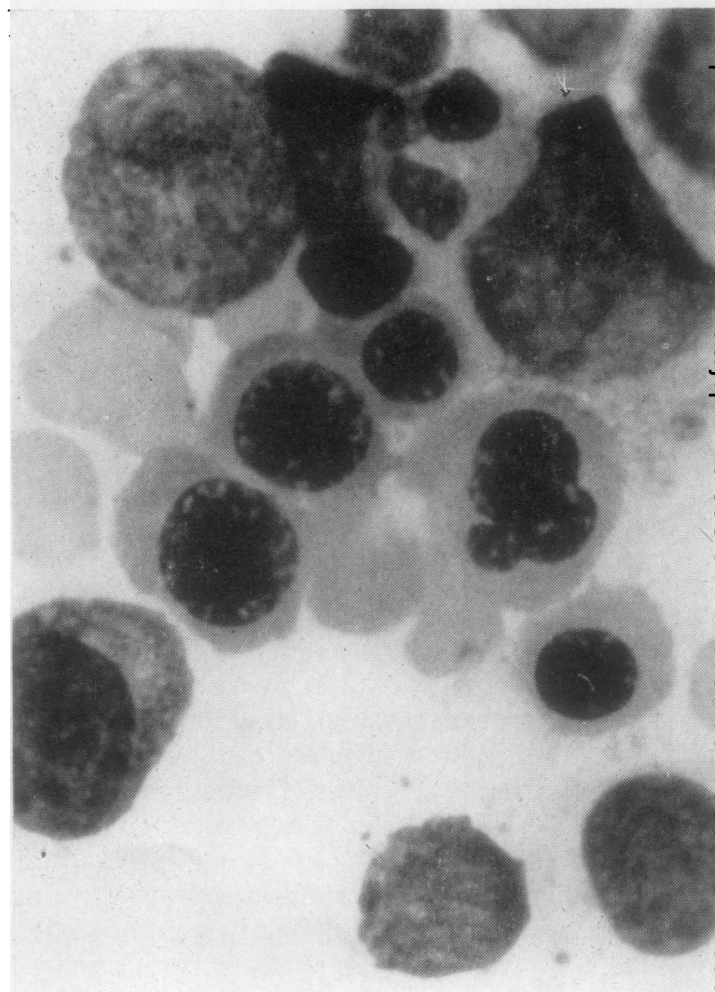

FIG. 3

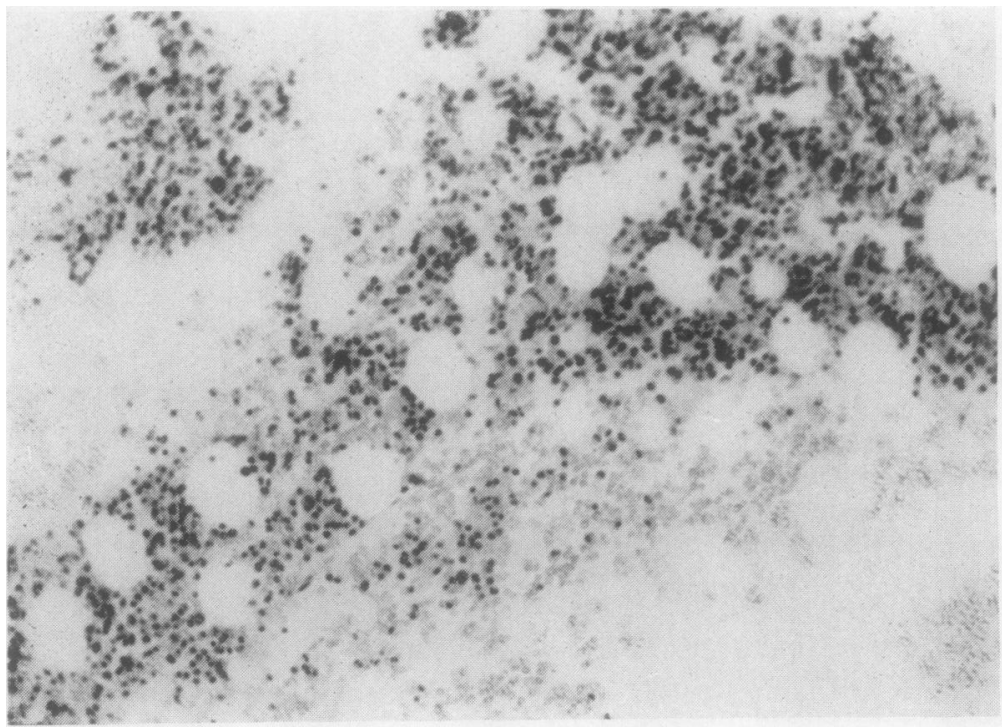

FIG. 2. Case 1. Very marked marrow hyperplasia affecting alP. elements. Megakaryocytic components very pronounced. NS sarcoid-like granulomata. $H$. and $E . \times 200$.

옥

FIG. 3. Case 1. Selected field 을 of marrow smear to show N transitional megaloblastic os transformation of erythroid $\mathrm{N}$ series and polyploidy of one celN Howell-Jolly body out of focus. $\sigma$ Shift to the left of the myeloid series. Leishman. $\times 1,900$.

FIG. 4. Case 1. Marrow sample 15 months after that shown in Figures 2 and 3. $H$. and $E . \times 200$. 


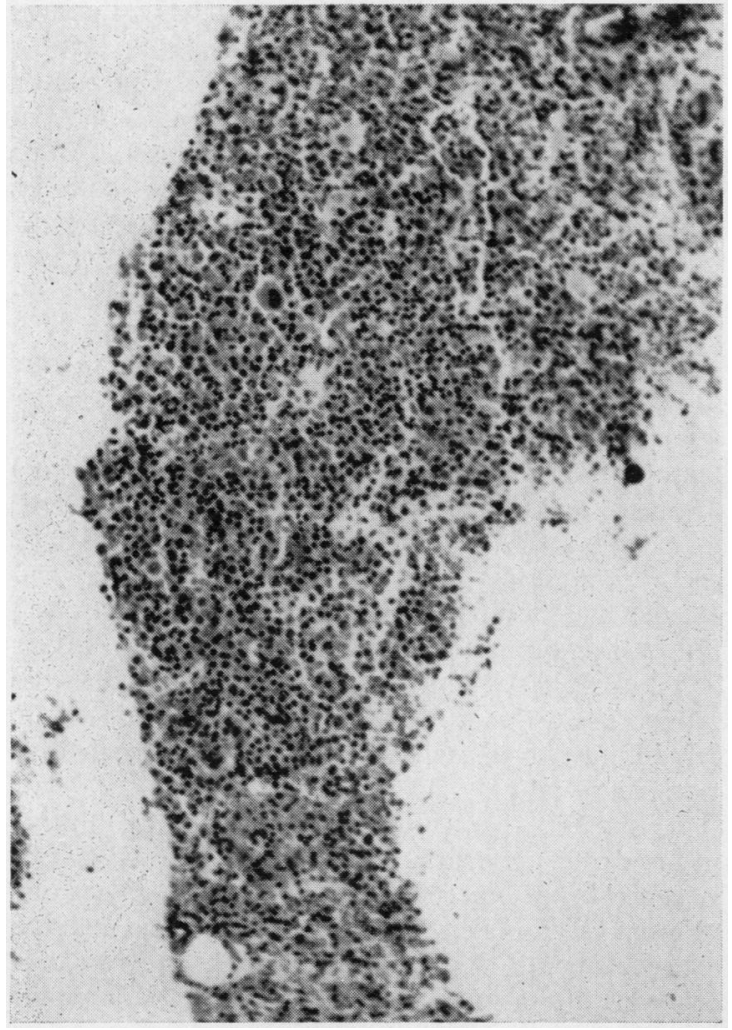

FIG. 5. Case 3. Extreme hyperplasia of sternal marrow affecting all elements, but megakaryocytic component not as marked as in case 1. H. and E. $\times 200$.

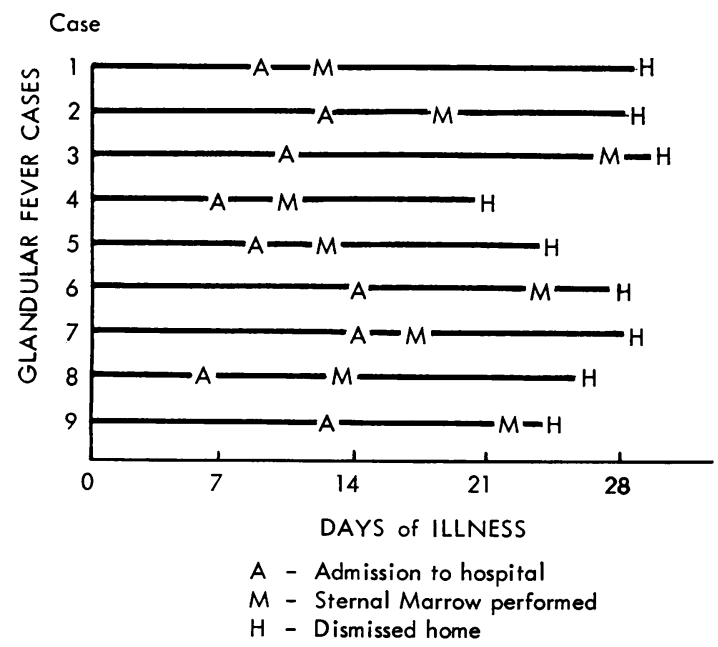

FIG. 6. Timing of events in nine cases of glandular fever.
In order to corroborate further, if possible, our benign interpretation of these marrow findings at the time of their first presentation, we asked for the cooperation of case 3 who was at that time also in hospital suffering from Paul-Bunnell-positive glandular fever. This permission was readily given and a marrow with a maximum degree of hyperplasia was obtained (Fig. 5). Sarcoid-like follicles were absent. The hyperplasia again affected all four elements, namely, erythroid, myeloid, megakaryocytic, and reticulum cells. The $\mathrm{M} / \mathrm{E}$ ratio was $1 \cdot 0 / 1 \cdot 5$ and both

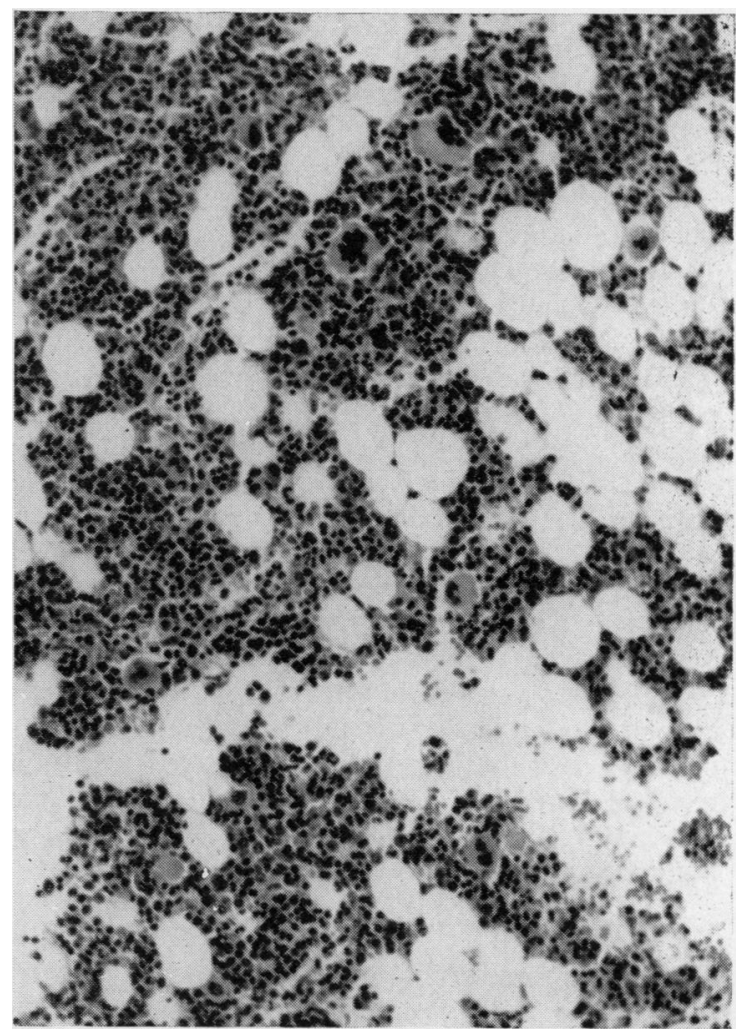

FIG. 7. Case 4. Least degree of marrow hyperplasia in the whole series. Hyperplasia is predominantly erythroid, but other elements have not escaped. $H$. and $E . \times 200$.

series showed a marked shift to the left but without apparent arrest of maturation. In this instance, however, erythropoiesis was frankly normoblastic, Howell-Jolly bodies and polyploidy were absent, and mitosis was not abnormally frequent. The megakaryocytic hyperplasia tended to be focal rather than diffuse and showed no convincing shift to the left in this instance. We considered that the findings in this confirmed case of glandular fever went some way to confirming our interpretation of the findings in case 1 , and then considered whether or not the difference in 
cytological detail might not be due to the fact that the sample from case 1 had been taken near the height of the patient's illness, whereas the sample from case 3 had been taken well into the convalescent period, indeed three days before his discharge home. To determine if this suggestion was accurate it was decided to embark on a short investigation of other cases (nos. 2 and 4-9) varying the interval of marrow study in order to study the evolution (or devolution) of the process (Fig. 6). In summary, we can state that all cases showed hyperplasia similar to that described above, but none was as extreme as in case 1 . The hyperplasia was least in case 4 (Fig. 7), and in case 5 it was as extreme as in case 3. All other examples occupied an intermediate position. All cases showed hyperplasia of all four marrow elements and the $M / E$ ratio varied from $3 \cdot 0 / 1.0$ for case 9 to $1 \cdot 0 / 1 \cdot 5$ for case 2. None of these nine cases showed sarcoid-like follicles and none the erythraemic features of case 1. The hyperplasia in all cases was accompanied by a shift to the left of all elements to a greater or lesser degree. Case 9 showed transitional megaloblastic features and case 3 showed occasional Howell-Jolly bodies. All patients had a varied megakaryocytic hyperplasia, and this was accompanied in almost all cases by low normal platelet levels. None had purpura. It was not possible to determine, however, at what stage the marrow hyperplasia was maximal. This would have required serial studies on each patient and was not considered to be a justifiable procedure.

Thus, over a period of four months, evidence was accumulated in favour of our original interpretation of the marrow findings in case 1 , and this impression received further support when the marrow was examined again 15 months later and showed a marked spontaneous reversion towards normality.

\section{DISCUSSION}

Glandular fever is a common disease and the marrow findings are well established but emphasis, in current texts, for example, is usually placed on the presence of the sarcoid-like granulomata illustrated in Figure 1. These granulomata, however, are not regularly found, as our series shows, and we wish to draw attention to the pronounced hyperplasia more commonly encountered and to the fact that this affects erythroid, myeloid, megakaryocytic, and reticulum cell elements; these are the features emphasized by the earlier workers. Thus, generalized hyperplasia was mentioned by Limarzi et al (1946), Campbell (1948), Hovde and Sundberg (1950), and was implied by Ogilvie and Parry (1952). Erythroid hyperplasia was reported by Morrison and Samwick (1939) and Volpe et al (1953). Myeloid hyperplasia was noted by Vogel and Bassen (1939),
Mendell et al (1942), Halcrow et al (1943), Limarzi et al (1946), and Custer and Smith (1948). Mega- -9 karyocytic hyperplasia was recorded by Limarzi et ale (1946), Hovde et al (1950), and Volpe et al (1953), but usually occurs accompanying hyperplasia of other $\vec{\Phi}$ components; it does not arise as the sole oro predominant finding unless there is frank purpurain (Kutzer and Allen, 1950). Schleicher's two cases $\overrightarrow{0}$ (1949) showed predominant reticulum cell hyper-plasia which was both diffuse as well as focal.

The absence of sarcoid-like granulomata in ours series is also in accord with previous reports.? Campbell (1948), who first drew attention to this feature, noted sarcoid-like granulomata in 12 of hisं 15 cases, and Schleicher (1949) found them in botho of his cases. Limarzi et al (1946), however, did not ${ }^{\omega}$ report granulomata in any of their 25 cases, and Hovde and Sundberg (1950), whose article is well ${ }_{Z}^{-}$ illustrated, reported granulomata in $48 \%$ of theirơ 23 cases. Pease (1956) states that granulomata were numerous in one-third of her series, but all of the remaining two-thirds showed lesions although they were very scanty.

It is clear, therefore, that the common finding in the earlier reported cases, and of our own group, is generalized hyperplasia, and this may affect oneo or more marrow elements to a greater degree than the other elements. It is understandable that various early manifestations of the malignant reticuloses or of the myeloproliferative disorders should be considered if the normal lymph follicles of the marrow undergo marked hyperplasia. Indeed, the present findings are those which commonly accompany Hodgkin's disease in the absence of marrow involvement (Wintrobe, 1956). Case 1 in particular caused such a difficulty because the degree of hyper- -0 plasia of all elements was so extreme. The fact 3 . that, as field after field was scrutinized, assessment $\varrho$ swung from Di Guiglielmo's syndrome to early’ myeloid leukaemia to megakaryocytic myelosis too Hodgkin's disease and to early reticulosarcoma when there was no support from clinical or haema-을. tological assessment for any of these diagnoses, $N$ reflects the extreme degree of hyperplasia which mayo arise, and in case 1 it affected all marrow elements. $\mathbb{O}$ It is of interest that the splenectomy specimen of one of Milne's cases (1945) was reported at first as beingo the seat of Hodgkin's disease. Our other caseso showed similar trends, but none of these cases was $\frac{\text { }}{\Phi}$ as extreme in pathological findings as was case $1 . \stackrel{+}{+}$ The difficulty which might be encountered by $\mathrm{a}_{0}$ pathologist examining such marrows when accompanying clinical details were few, and when there was no accompanying recent peripheral blood film, is easy $\overrightarrow{\mathbb{Q}}$ to appreciate. In addition, case 7 showed a mild eosinophilia. This was accompanied later by a $3 \%$ 
eosinophilia in the peripheral blood, a relatively common later feature of glandular fever (Tidy, 1934; Bernstein, 1940; Halcrow et al, 1943; Kauffman, 1950), and this appearance in the marrow, together with the reticulum cell hyperplasia, caused the diagnosis of toxoplasmosis to be considered. In no case was it considered necessary or justifiable to have a lymph node biopsy.

Our patients' marrow specimens showed no specific feature to guide the pathologist to the diagnosis of glandular fever. Knowledge of the peripheral blood findings and of other investigations is necessary. It is clear, however, that generalized hyperplasia accompanied by varying degrees of shift to the left of all marrow components, including the reticulum cells, is not a finding likely to be encountered frequently in haematological practice. We wish to emphasize, however, that our experience of marrow examination in diseases of accepted viral aetiology is very limited. In the latter circumstance, study of the marrow has evolved from an unexpected and unexplained peripheral blood finding, rather than from a need to study primarily the effect of the known viral agent on the marrow. Therefore, it may be that our findings in the marrow in glandular fever, which corroborate those of most other workers, are common to several viral infections, with the qualification that a whole range of different marrow states is known to accompany infections in general, including acute arrest of haemopoiesis (Chanarin, Barkham, Peacock, and Stamp, 1964).

The different emphasis of the hyperplastic process on one cell line or another and from one case to another is, in our opinion, a reflection of the marrow state at the time of onset of the hyperplastic process. Further, if at the time of the hyperplastic stimulus the patient's reserves of one or more haemopoietic principles (the term is used in its broadest interpretation) are marginal, then highly unusual cytological features may follow due to the rapid and total depletion of these reserves. This suggestion was offered by Mengel et al (1964) to explain the findings in their case, and could also explain the bizarre findings in our case 1 although no depletion was found as far as our incomplete investigations went.

The concomitant finding of reticuloendothelial granulomata in the marrow, taken in conjunction with the not uncommon finding of peripheral blood eosinophilia in convalescence, may reflect an imbalance between cellular and humoral antibody mechanisms, together possibly with an element of hypersensitivity having evolved during the illness. It is not known whether or not the patients who show these granulomata in the marrow are the ones who customarily show eosinophilia in convalescence. The findings in one case (no. 7) do not support this suggestion. Since repeated attacks of proven glandular fever in one patient appear to be very rare, it is inferred that the illness results from one aetiological agent rather than from several agents. If the present results are included with all post-1945 reports on the subject, and accepting that $100 \%$ of Pease's glandular fever marrows showed granulomata, then granulomata have been reported in nearly half ( 39 of 88 ) of the patients whose marrows have been examined. The incidence $(44.3 \%)$ gives no indication whether the granulomata are initiated by the agent or whether the presence or absence of granulomata is a reflection of the patient's idiosyncrasy to the illness. However, since two series (Limarzi et al (1946) and our own) failed to reveal any incidence of granulomata, while two reports (Campbell, 1948; Pease, 1956) showed a high incidence of granulomata, it may be suggested that these extremes of results reflect population differences (rather than individual differences) in response to the same agent. Otherwise the results may suggest that more than one agent can be responsible for the illness.

It is not possible to offer a general explanation for the consistently present marked hyperplasia which has been encountered except that it appears to be part of a general state of cell proliferation. None of our cases showed any of the usual features favouring haemolytic anaemia. All cases showed a relative and absolute neutropenia, and thus myeloid hyperplasia with a temporary shift to the left might be expected, and has been noted. Although none of our series had purpura, all had low platelet levels. This finding is well known (Carter, 1965), and could be responsible for part of the megakaryocytic hyperplasia. Overt anaemia, agranulocytosis, and thrombocytopenia, however, are not uncommon in glandular fever (Tidy, 1934; Bernstein, 1940; Carter, 1966), and each of these will contribute to hyperplasia of the related marrow elements.

General marrow stimulation of all cellular elements within the presumed incubation period could also be a readily accepted explanation, and Metcalf and Wahren (1958) have recently demonstrated a bone marrow colony-stimulating activity of 44 to $100 \%$ of sera from patients with infectious mononucleosis. Epstein and Brecher (1965) have studied DNA and RNA synthesis of the circulating atypical lymphocytes, and their results, which confirm those of Gavosta, Pileri, and Maraini (1959), show that there is a burst of active proliferation, greatest during the first two weeks of illness, and gradually declining during the next three weeks, even although these atypical lymphocytes may persist in the circulating blood for a much longer period. We assume that these findings reflect the effect of some undetermined 
stimulus upon the reticuloendothelial and lymphoid systems, and the evidence presented by several reports of the bone marrow findings in glandular fever would now suggest that the same stimulus affects the bone marrow, possibly through the medium of the haemopoietic stem cells (Moffatt, Rosse, and Yoffey, 1967; Miller and Mitchell, 1967). However, the findings of almost maximal hyperplasia in our cases 1 and 4, whose marrow was studied within three days of admission to hospital, might suggest that the stimulus occurred much earlier, even in the earlier part of the incubation period which is reported by Hoagland (1964) to be about 33 to 49 days, and before the onset of symptoms. This suggestion receives support from those articles reporting peripheral blood changes before the onset of symptoms (Barrett, 1941; Halcrow et al, 1943).

We wish to thank Mr T. Gallie, Miss C. Mackay, and $\mathrm{Mr}$ W. Marshall for technical assistance. We are also very grateful to $\mathrm{Dr} \mathrm{H}$. E. Hutchison, Haematology Department, Western Infirmary, for his help in preparing the text, and for allowing us to publish Figure 1. Mr R. Callander, Department of Medical Illustration, Glasgow University, prepared Fig. 6, and Mr R. Summers the other illustrations.

\section{REFERENCES}

Allen, F. H., Jr, and Kellner, A. (1947). Amer. J. Path., 23, 463. Barrett, A. M. (1941). J. Hyg. (Lond.), 41, 330.

Bernstein, A. (1940). Medicine (Baltimore), 19, 85.

Britton, C. J. C. (1963). Whitby and Britton's Disorders of the Blood, 9 th ed. Churchill, London.
Campbell, A. C. P. (1948). J. Path. Bact., 60, 629.

Carter, R. L. (1965). Blood, 25, 817

- (1966). J.clin. Pat

Chanarin, I., Barkham, P., Peacock, M., and Stamp, T. C. B. (1964) Brit. J. Haemat., 10, 43.

Custer, R. P., and Smith, E. B. (1948). Blood, 3, 830.

Davidsohn, I., and Lee, C. L. (1964). Amer. J. clin. Path., 41, 115.

Du Bois, A. H. (1930). Acta med. scand., 73, 237.

Epstein, L. B., and Brecher, G. (1965). Blood, 25, 197.

Freeman, W. (1936). Amer. J. clin. Path., 6, 185.

Gavosta, F., Pileri, A., and Maraini, G. (1959). Nature (Lond.), ஸి

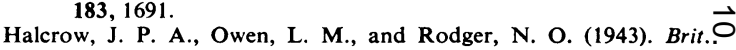
med. J., $2,443$.

Hoagland, R. J. (1964). Amer. J. publ. Hlth, 54, 1699.

Hovde, R. F., and Sundberg, R. D. (1950). Blood, 5, 209.

Hutchison, H. E. (1953). Ibid., 8, 236.

Israëls, M. C. G. (1941). Lancet, 1, 260.

Kauffman, R. E. (1950). Amer. J. med. Sci., 219, 206.

Kutzer, M., and Allen, E. G. (1950). N.Y. St. J. Med., 50, 1131.

Limarzi, L. R., Paul, J. T., and Poncher, H. G. (1946). J. Lab. clin. Med., 31, 1079.

Mendell, T. H., Meranze, D. R., and Meranze, T. (1942). Ann. intern.œ్ Med., 16, 1180.

Mengel, C. E., Wallace, A. G., and McDaniel, H. G. (1964). Arch. 음 intern. Med., 114, 333.

Metcalf, D., and Wahren, B. (1958). Brit. med. J., 3, 99.

Miller, J. F. A. P., and Mitchell, G. F. (1967). Nature (Lond.), 216, 659.

Milne, J. (1945). New Engl. J. Med., 233, 727.

Moffatt, D. J., Rosse, C., and Yoffey, J. M. (1967). Lancet, 2, 547.

Morrison, M., and Samwick, A. A. (1939). Amer. J. med. Sci., 198, 758.

Ogilvie, C. M., and Parry, T. E. (1952). Brit. med. J., 2, 977.

Pease, G. L. (1956). Blood, 11, 720.

Schleicher, E. M. (1949). Acta haemat. (Basel), 2, 242.

Scott, R. B. (1939). Quart J. Med., 8, 127.

Tidy, H. L. (1934). Lancet, 2, 180 and 236.

Vogel, P., and Bassen, F. A. (1939). Amer. J. Dis. Child., 57, 245.

Volpe, R., Sparks, B. B., and Mautner, L. S. (1953). Canad. med. Ass J., 68, 269.

Wintrobe, M. M. (1956). Clinical Hematology. 4th ed., p. 1026. Kimpton, London. 